\title{
Análise Numérica de Convecção Forçada em Arranjo de Obstáculos dentro de um Canal
}

\author{
Márcio AntonioBazani Amarildo TabonePaschoalini Edilson Guimarães de \\ Souza Alex Pereira da Cunha \\ Depto de Engenharia Mecânica, FEIS, UNESP, 15385-000, Ilha Solteira, SP \\ bazani@dem.feis.unesp.br; \\ tabone@dem.feis.unesp.br \\ edilsonguimaraesdesouza@gmail.com \\ alex.cunha@aluno.feis.unesp.br
}

\begin{abstract}
RESUMO
Com o grande desenvolvimento da tecnologia, houve um aumento no empacotamento eletrônico, com o consequente aumento da dissipação de potência térmica. $\mathrm{O}$ desconhecimento da potência se tornou um entrave, fazendo com que os fabricantes superdimensionem o sistema de resfriamento de seus produtos [1]. O objetivo deste trabalho é analisar numericamente o processo de convecção forçada em arranjo de obstáculos dentro de um canal, cuja velocidade de resfriamento esteja entre 2 a $4 \mathrm{~m} / \mathrm{s}$. A Figura 1 mostra o domínio computacional onde são regidas as equações clássicas de conservação (massa, momentum e energia e modelo de turbulência k-epsilon (k-E) e RNG). O software utilizado para a solução do problema é o ANSYS FLUENT ${ }^{\circledR}$. As condições de contorno foram temperatura e velocidade de entrada uniformes, fluxo de calor conhecido nos componentes e superfícies laterais e da base adiabáticas, as condições na saída são calculadas pelo software.
\end{abstract}

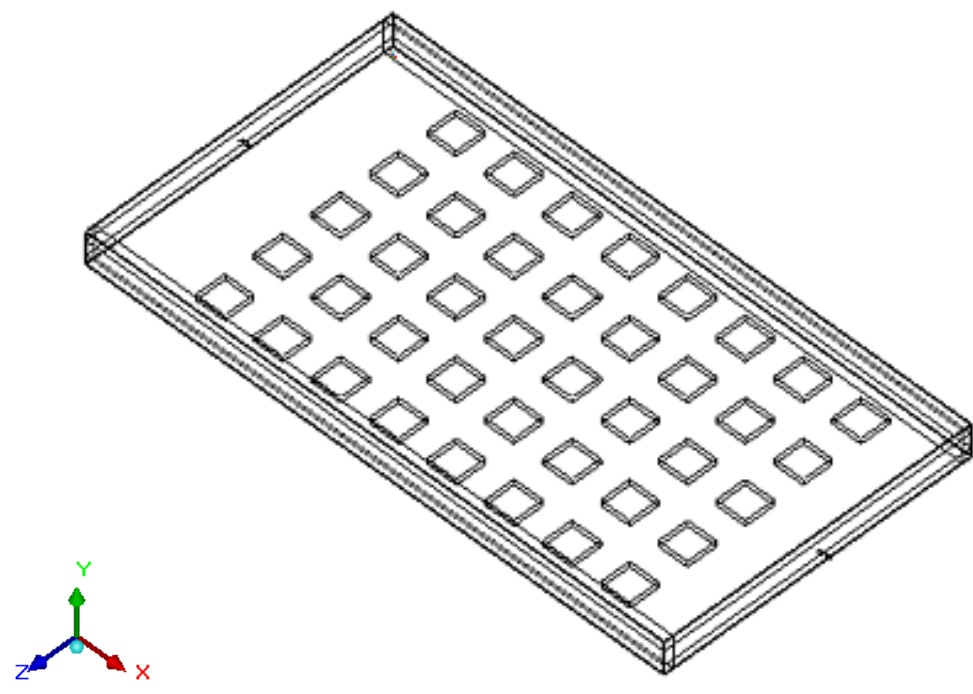

Figura 1: Domínio computacional

Com as condições de contorno definidas, o próximo passo é a resolução do sistema de equações geradas pelo próprio software, fornecendo os campos de pressão, velocidade e temperatura em todo o domínio computacional [2]. De posse desses dados, calcula-se o coeficiente de transferência de calor para cada componente de forma a ser definido um número de Nusselt que forneça uma importante relação entre a convecção e condução do fuido de trabalho [3]. Para ser atingida a convergência dos resultados uma malha, com 580000 elementos foi gerada de modo que o maior resíduo entre todas as equações governantes fosse de $10^{-5}$, conforme a Figura 2. 


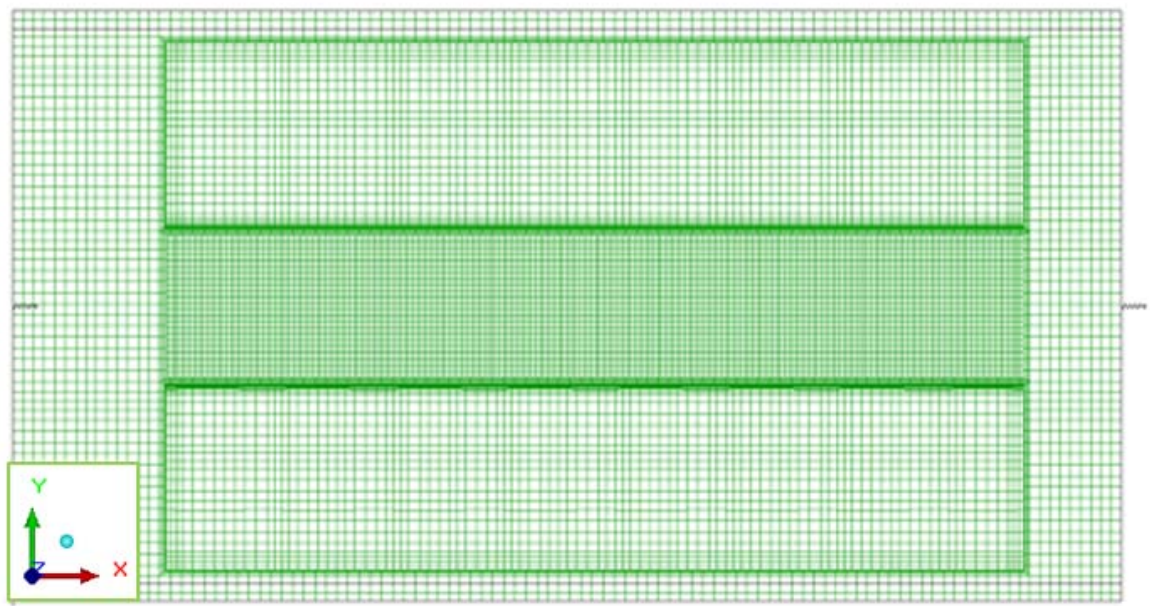

Figura 2: Malha do domínio computacional

Observa-se claramente, através da Figura 3, que os modelos de turbulência RNG e modelo kepsilon (k-E) fornecem uma estimativa do coeficiente de transferência de calor para cada componente ativo. É possível então verificar a influência de cada elemento ativo em seu vizinho através do coeficiente de influência que será estudado a posteriori e como consequência, sabendo a velocidade de escoamento, haverá condições de se ter uma relação clara entre potencia e variação de temperatura.

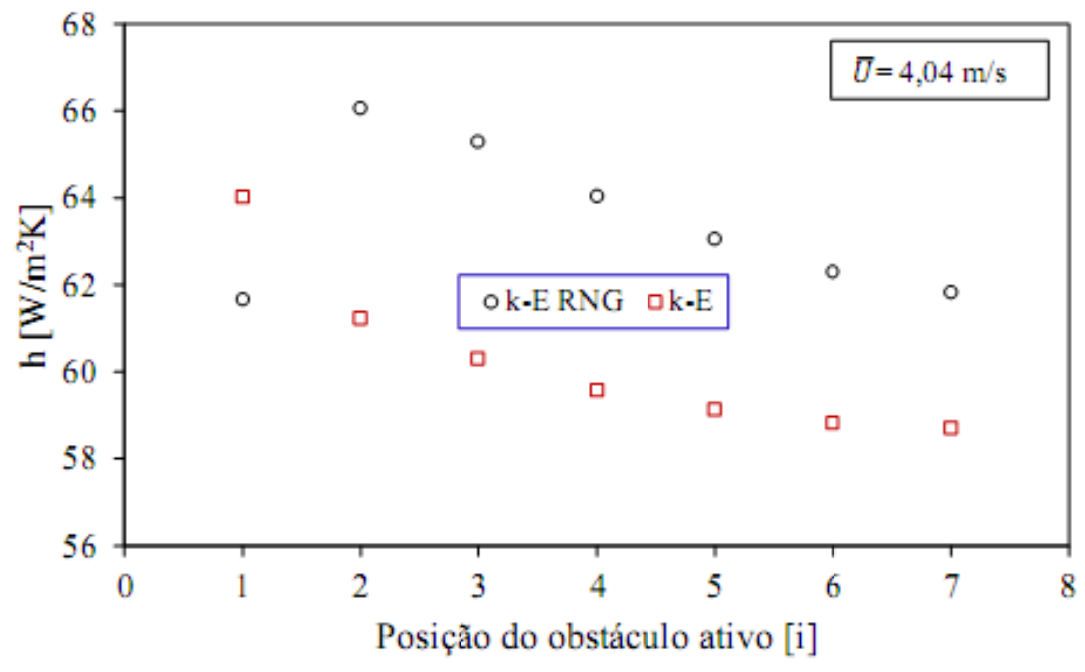

Figura 3: Coeficiente de convecção forçada

\section{Referências}

[1] A. Bejan, “Transferencia de calor”, Edgar Blucher, São Paulo, 2004R.

[2] J. Moffat, What is new in convective heat transfer? International Journal of Heat and Fluid Flow, v.19, p.90-101, 1998.

[3] T.A. Alves, C.A.C. Altemani. Convective cooling of the three discrete heat source in channel flow. Journal of Brazilian Society of Mechanical Science and Engineering, v.30, n.3, p.245-252, 2008. 